\title{
A failure to obtain magnetic discrimination in the pigeon
}

\author{
BRENT ALSOP \\ University of Auckland, Auckland, New Zealand
}

\begin{abstract}
Six pigeons were trained on a multiple-concurrent schedule. During both multiple-schedule components, two response keys were available. In Component 1 , responses to the left key were reinforced on a variable-interval 45-sec schedule, whereas responses to the right key were not reinforced. In Component 2, these contingencies were reversed. Following each reinforcer, the component next presented was chosen randomly with equal probability. The two components were differentially signaled by presentation of various stimuli during Component 1 . Over the course of the experiment, these stimuli were various intensities of light, a noise, and various fluctuating and static magnetic fields. While subjects showed good discrimination of the light and noise stimuli, no stimulus control using the magnetic fields was obtained.
\end{abstract}

Researchers have reported that Earth's magnetic field serves as a stimulus that affects behavior in a variety of species. Studies have shown that mud bacteria (Kalmijn \& Blakemore, 1978), bees (Gould, Kirschvink, Deffeyes, \& Brines, 1980), flies (Becker, 1963), elasmobranch fish (Kalmijn, 1978), salamanders (Phillips \& Alder, 1978), and even humans (Baker, 1980) may be sensitive to magnetic fields. However, the most extensive research in this area has been conducted using avians, in particular, the pigeon.

Observations and experiments in the field have provided the bulk of the evidence that pigeons are sensitive to magnetic fields. Such studies have investigated the effects of regional magnetic anomalies on the flight paths of trained homing pigeons (e.g., Walcott, 1978), the effects of attaching magnets to pigeons on subsequent homing (Keeton, 1972; Walcott \& Green, 1974), the effects of transportation in inversed vertical magnetic fields on homing (Kiepenheurer, 1978), and the effects of magnetic "storms"' on pigeon flight (e.g., Keeton, Larkin, \& Windsor, 1974). Naturally, these results have led to laboratory experiments aiming to provide quantitative data on this phenomenon, such as measures of the sensitivity of pigeons to changes in the intensity or the angle of an applied magnetic field. However, the success of this research has been extremely limited.

Reille (1968) reported successful classical conditioning of the cardiac rhythm of a pigeon to stimuli consisting of either static or fluctuating magnetic fields of approximately Earth strength. While the actual level of the response was low, the positive result was encouraging.

\footnotetext{
I thank Michael Davison for his guidance with this experiment and manuscript, and the staff and students who helped run it. I also thank the New Zealand University Grants Committee for equipment grants to Michael Davison and for the Postgraduate Scholarship that allows me to continue my research. Reprints may be obtained from Brent Alsop, Department of Psychology, University of Auckland, Private Bag, Auckland, New Zealand.
}

However, replications of this experiment have not been successful. Major studies by Kreithen and Keeton (1974) and Beaugrand (1976), using 97 and 38 pigeons, respectively, and employing a variety of magnetic fields as stimuli, failed to produce any conditioning of heart-rate activity.

Other experimenters have attempted to use magnetic fields as stimuli in operant conditioning paradigms. Meyer and Lambe (1966) used a magnetic field as the discriminative stimulus between variable-interval (VI) 60 -sec schedules and extinction (Ext) components of a multiple schedule. They found no differential control of behavior by the magnetic stimulus. Bookman (1977) and M. Davison (personal communication, 1983) report that other unpublished operant experiments have also failed to get pigeons to discriminate between magnetic stimuli. A study by Bookman (1977) stands as a lone exception. He used a discrete-trial procedure in which mated pairs of pigeons traveled the length of a 4-m tunnel and then chose between two goalboxes. A series of electric coils along the outside of the tunnel could produce a magnetic field. When these were activated, one particular box gave access to grain; when these were not activated, the other goalbox gave access to grain. The relative number of correct responses was significantly greater than chance only for trials in which the pigeons spent at least $3 \mathrm{sec}$ "fluttering" inside the tunnel. Bookman interpreted this result as showing that increased motor activity might be necessary to condition pigeon behavior to magnetic cues. However, to this author's knowledge, no successful replication of this experiment has appeared in the literature.

The present experiment attempted to demonstrate discrimination of an applied magnetic field by pigeons. It employed a standard experimental chamber and a freeoperant paradigm. In this multiple-concurrent schedule procedure, two response keys were concurrently available in each component of a multiple schedule. During one component, responses to the left key were reinforced 
on a VI 45-sec schedule whereas responses to the right key produced no reinforcers. In the other component, these contingencies were reversed. Over the course of the experiment, the two components were differentially signaled by the presence or absence of a variety of stimuli. These included various applied magnetic fields, various intensities of light, noise, and combinations of these three stimuli.

The results were analyzed using Davison and Tustin's (1978) behavioral model of signal detection performance. This provided an unbiased estimate of discriminability between the component stimuli $(\log d)$, which is equivalent to $d^{\prime}$ (Green \& Swets, 1966) and is calculated by the following equation:

$$
\log d=\frac{1}{2}\left[\log \left(\frac{P w}{P x}\right)+\log \left(\frac{P z}{P y}\right)\right],
$$

where $P w$ and $P x$ are responses to the left and right keys, respectively, during Component 1 of the multiple schedule, and $P y$ and $P z$ are responses to the left and right keys, respectively, during Component 2 of the multiple schedule (for a detailed account of this analysis, see McCarthy, Davison, \& Jenkins, 1982).

\section{METHOD}

Subjects

Six homing pigeons, numbered 201 to 206 , were maintained at $85 \% \pm 15 \mathrm{~g}$ of their free-feeding body weights. Water and grit were freely available in the home cages and supplementary postsession mixed grain was provided as required to maintain their designated body weights. All birds had experience on free-operant procedures but had no explicit training with the stimuli used in this experiment.

\section{Apparatus}

Conventional solid-state equipment and impulse counters situated remotely from the wooden experimental chamber controlled all experimental events and recorded the data. The chamber, $33 \mathrm{~cm}$ high, $31 \mathrm{~cm}$ deep, and $33 \mathrm{~cm}$ wide, contained three response keys, $2 \mathrm{~cm}$ in diameter, $9.5 \mathrm{~cm}$ apart, and $23.5 \mathrm{~cm}$ above the grid floor. The center key was dark and inoperative throughout, and in Conditions 4 to 24 , a naked $24-\mathrm{V}, .05-\mathrm{A}, 1.2-\mathrm{W}$ bulb was mounted in front of it. The side keys could be transilluminated white, and when lit were operated by pecks exceeding .1 N. Reinforcement was provided by a grain hopper situated below the center key and $9.5 \mathrm{~cm}$ above the grid floor. During reinforcement, all stimuli and key lights were extinguished and the hopper was raised and illuminated for 3 sec. The only sources of illumination in the chamber were the key lights, the hopper light, and in some conditions the bulb mounted before the center key. An exhaust fan served to ventilate the chamber and mask external noise.

A copper wire coil, $15 \mathrm{~cm}$ in diameter, $20 \Omega$, and 100 turns, was attached to the exterior surface of the chamber. A line traveling axially from the center of the coil passed $1.5 \mathrm{~cm}$ above and $1.5 \mathrm{~cm}$ in front of the keys. When activated, this coil produced a magnetic field at right angles across the face of the keys. A compass mounted on the exterior of the chamber served to check that the magnetic field was operating. A converted relay situated behind the keys produced "noise" when activated.

\section{Procedure}

All experimental conditions employed a multiple-concurrent schedule. During Component 1 of the multiple schedule, both side keys were lit white. Responses to the left key were reinforced on a VI 45-sec schedule; responses to the right key produced no reinforcers. During Component 2 of the multiple schedule, both side keys were again lit white but responses to the left key produced no reinforcers and responses to the right key were reinforced on a VI 45-sec schedule. During both components, there was a 2 -sec changeover delay between the concurrent schedules; that is, a response on one key could not produce a reinforcer, even though it was arranged by a VI schedule, until $2 \mathrm{sec}$ had elapsed since the first peck on that key following responses to the other key. Each component was in operation until a reinforcer was obtained. Following a reinforcer, the component next presented was chosen randomly with equal probability. Across conditions, various stimuli were presented during Component 1 and were always absent dur-

\section{Table 1}

The Sequence of Experimental Conditions, Number of Sessions of Training in Each, and the Stimuli Present in Component 1

\begin{tabular}{|c|c|c|}
\hline Condition & Sessions & Stimuli in Component 1 \\
\hline 1 & 23 & No differential stimuli \\
\hline 2 & 10 & Magnetic Field $\mathrm{A}, 45^{\circ}$ deflection \\
\hline 3 & 6 & Magnetic Field A, $135^{\circ}$ deflection \\
\hline 4 & 11 & $\begin{array}{l}\text { Magnetic Field } \mathrm{A}, 135^{\circ} \text { deflection } \\
\text { Lit bulb, } 17.40 \mathrm{~cd} / \mathrm{m}^{2}\end{array}$ \\
\hline 5 & 5 & $\begin{array}{l}\text { Magnetic Field A, } 135^{\circ} \text { deflection } \\
\text { Lit bulb, } 9.56 \mathrm{~cd} / \mathrm{m}^{2}\end{array}$ \\
\hline 6 & 4 & $\begin{array}{l}\text { Magnetic Field A, } 135^{\circ} \text { deflection } \\
\text { Lit bulb, } 6.10 \mathrm{~cd} / \mathrm{m}^{2}\end{array}$ \\
\hline 7 & 2 & $\begin{array}{l}\text { Magnetic Field A, } 135^{\circ} \text { deflection } \\
\text { Lit bulb, } 1.22 \mathrm{~cd} / \mathrm{m}^{2}\end{array}$ \\
\hline 8 & 5 & $\begin{array}{l}\text { Magnetic Field A, } 135^{\circ} \text { deflection } \\
\text { Lit bulb, } .21 \mathrm{~cd} / \mathrm{m}^{2}\end{array}$ \\
\hline 9 & 4 & $\begin{array}{l}\text { Magnetic Field A, } 135^{\circ} \text { deflection } \\
\text { Lit bulb, } .12 \mathrm{~cd} / \mathrm{m}^{2}\end{array}$ \\
\hline 10 & 3 & $\begin{array}{l}\text { Magnetic Field A, } 135^{\circ} \text { deflection } \\
\text { Lit bulb, } .06 \mathrm{~cd} / \mathrm{m}^{2}\end{array}$ \\
\hline 11 & 2 & $\begin{array}{l}\text { Magnetic Field A, } 135^{\circ} \text { deflection } \\
\text { Lit bulb, } .04 \mathrm{~cd} / \mathrm{m}^{2}\end{array}$ \\
\hline 12 & 8 & $\begin{array}{l}\text { Magnetic Field } \mathrm{A}, 135^{\circ} \text { deflection } \\
\text { Lit bulb, } .02 \mathrm{~cd} / \mathrm{m}^{2}\end{array}$ \\
\hline 13 & 4 & Magnetic Field A, $135^{\circ}$ deflection \\
\hline 14 & 8 & $\begin{array}{l}\text { Noise } \\
\text { Lit bulb, } .02 \mathrm{~cd} / \mathrm{m}^{2}\end{array}$ \\
\hline 15 & 8 & Noise \\
\hline 16 & 4 & $\begin{array}{l}\text { Noise } \\
\text { Lit bulb, } .02 \mathrm{~cd} / \mathrm{m}^{2}\end{array}$ \\
\hline 17 & 7 & $\begin{array}{l}\text { Magnetic Field B, } 135^{\circ} \text { deflection } \\
\text { Lit bulb, } .02 \mathrm{~cd} / \mathrm{m}^{2}\end{array}$ \\
\hline 18 & 11 & Magnetic Field $\mathrm{B}, 135^{\circ}$ deflection \\
\hline 19 & 15 & $\begin{array}{l}\text { Magnetic Field } B, 135^{\circ} \text { deflection } \\
\text { Pulsing } 3 \mathrm{sec} \text { on, } 3 \mathrm{sec} \text { off } \\
\text { Lit bulb, .02 cd } / \mathrm{m}^{2}\end{array}$ \\
\hline 20 & 9 & $\begin{array}{l}\text { Magnetic Field B, } 135^{\circ} \text { deflection } \\
\text { Pulsing } 3 \mathrm{sec} \text { on, } 3 \mathrm{sec} \text { off }\end{array}$ \\
\hline 21 & 10 & $\begin{array}{l}\text { Magnetic Field } \mathrm{B}, 135^{\circ} \text { deflection } \\
\text { Pulsing } 1 \mathrm{sec} \text { on, } 3 \mathrm{sec} \text { off } \\
\text { Lit bulb, .02 cd/m } / \mathrm{m}^{2}\end{array}$ \\
\hline 22 & 12 & $\begin{array}{l}\text { Magnetic Field } B, 135^{\circ} \text { deflection } \\
\text { Pulsing } 1 \mathrm{sec} \text { on, } 3 \mathrm{sec} \text { off }\end{array}$ \\
\hline 23 & 9 & $\begin{array}{l}\text { Magnetic Field B, } 135^{\circ} \text { deflection } \\
\text { Pulsing } 2 \mathrm{sec} \text { on, } 3 \mathrm{sec} \text { off } \\
\text { Lit bulb, } 1.91 \mathrm{~cd} / \mathrm{m}^{2} \\
\text { Pulsing } 2 \mathrm{sec} \text { on, } 3 \mathrm{sec} \text { off }\end{array}$ \\
\hline 24 & 7 & $\begin{array}{l}\text { Magnetic Field B, } 135^{\circ} \text { deflection } \\
\text { Pulsing } 2 \text { sec on, } 3 \text { sec off }\end{array}$ \\
\hline
\end{tabular}


ing Component 2. The stimuli, the sequence of experimental conditions, and the number of sessions of training in each condition are shown in Table 1.

Since no initial training was necessary, the subjects were placed directly into Condition 1 . This was a baseline condition in that no differential stimuli were present in Component 1 or Component 2. In Condition 2, a .34-A current was passed through the coil during Component 1. This produced a magnetic field (Magnetic Field A), which varied in intensity as a function of the axial and radial distance from the coil. The intensity of the field at various points along the axis of the coil are shown in Table 2. The North of this applied magnetic field was approximately $45^{\circ}$ West of the ambient geomagnetic North present in Component 2. In Condition 3, the direction of the current was reversed and a magnetic field of identical intensity but with a North approximately $135^{\circ}$ East of ambient North was present in Component 1 . This orientation of the field was maintained for the remainder of the experiment.

Research has shown that discrimination along a difficult stimulus dimension can be enhanced by coupling those stimuli with a further easily discriminable set of stimuli, which are then gradually faded out (Terrace, 1963). So, during Component 1 of Condition 4 , both the magnetic field used in Condition 3 and the bulb mounted in front of the center key were activated. The intensity of the bulb was $17.40 \mathrm{~cd} / \mathrm{m}^{2}$. Then the intensity of the bulb was successively faded across Conditions 5 to 12 (Table 1), to a final $.02 \mathrm{~cd} / \mathrm{m}^{2}$. In Condition 13, a replication of Condition 3 , the applied magnetic field alone was presented during Component 1 .

The magnetic field was not used in the next three conditions. Instead, stimulus control using an auditory stimulus, traditionally a difficult stimulus dimension on which to train pigeons (Rudolph \& Van Houton, 1977), was attempted. During Condition 14, the lit bulb $\left(.02 \mathrm{~cd} / \mathrm{m}^{2}\right)$ and a noise produced by a converted relay were present in Component 1 . In Condition 15, Component 1 was signaled by the noise alone. Condition 16 was a replication of Condition 14.

In Condition 17 , the bulb $\left(.02 \mathrm{~cd} / \mathrm{m}^{2}\right)$ and an applied magnetic field were present in Component 1 . The orientation of the field was identical to that in Condition 3, but the current through the coil was now .56 A (Magnetic Field B). The field intensities at various points along the axis of the coil are shown in Table 2 . This current and orientation were used for the remainder of the experiment. In Condition 18, the magnetic field alone was present in Component 1.

The remaining conditions employed a fluctuating rather than a static applied magnetic field. If the subjects were sensitive to the magnetic field while it was changing, rather than to the actual change in orientation, then they might be able to discriminate between the presence or absence of a pulsing field. In Condition 19, both the lit bulb $\left(.02 \mathrm{~cd} / \mathrm{m}^{2}\right)$ and a pulsing magnetic field $(3 \mathrm{sec}$ on, $3 \mathrm{sec}$ off) were present in Component 1 . The pulsing field alone was present in Condition 20 . The duration of the pulse was shortened ( $1 \mathrm{sec}$ on, $3 \mathrm{sec}$ off) in Condition 21 and the lit bulb was reintro-

Table 2

Point Estimates of the Field Strength of the Applied Magnetic Field Along an Axial Line Extending Through the Center of the Coil Across the Face of the Keys

\begin{tabular}{ccccccc}
\hline Magnetic & \multicolumn{5}{c}{ Distance Along Axial Line } \\
\cline { 2 - 7 } Field & $5 \mathrm{~cm}$ & $10 \mathrm{~cm}$ & $15 \mathrm{~cm}$ & $20 \mathrm{~cm}$ & $25 \mathrm{~cm}$ & $30 \mathrm{~cm}$ \\
\hline A & 1.64 & .62 & .26 & .12 & .07 & .04 \\
B & 2.70 & 1.01 & .42 & .20 & .11 & .07 \\
\hline
\end{tabular}

Note-Field strength is measured in gauss (Earth-strength field is approximately $.50 \mathrm{G}$ ). The keys were $1.5 \mathrm{~cm}$ below and $1.5 \mathrm{~cm}$ across from the axial line. The left and right keys were approximately 7.8 and $31 \mathrm{~cm}$ from the coil respectively. Values are only for the induced field, not for the ambient and induced fields combined. duced. In Condition 22, the pulsing field alone was present in Component 1 .

Both the lit bulb $\left(1.91 \mathrm{~cd} / \mathrm{m}^{2}\right)$ and the magnetic field were pulsed ( $2 \mathrm{sec}$ on, $3 \mathrm{sec}$ off) during Component 1 in Condition 23. The intensity of the lit bulb was increased in order to produce effective pulsing. In Condition 24, the pulsing field alone was present in Component 1.

Experimental sessions were conducted daily. Each session started in blackout and terminated in blackout after 40 reinforcers were obtained or after $45 \mathrm{~min}$ had elapsed, whichever occurred sooner. The data collected for each bird at the end of each session consisted of the number of responses to the left and right keys during Component 1 , the number of responses to the left and right keys during Component 2 , and the number of reinforcers obtained on the left and right keys.

\section{RESULTS}

Unbiased estimates of the discriminability between the component stimuli $(\log d)$ were calculated using Equation 1 for each subject in each session. Performance in each condition was assessed from the mean $\log d$ taken across the last four sessions. For conditions with fewer than four sessions (Conditions 7, 10, and 11), the data points shown in Figure 1 were calculated from all the sessions conducted in that condition. Figure 1 shows these means plotted for each subject and condition.

In Condition 1, no discriminative stimuli were presented during Component 1 . Figure 1 clearly shows that the subjects did not discriminate between the two components (i.e., $\log d=0$ ). When the applied magnetic fields were introduced during Component 1 of Conditions 2 and 3 , there was no change in the degree of discriminability between the two components shown by the subjects (Figure 1).

Coupling the presence of the applied magnetic field with the onset of a naked bulb in Component 1 of Condition 4 dramatically improved discriminability between the two components for all subjects. As the intensity of the bulb was decreased across Conditions 5 to 12 , there was generally a decrease in discriminability. Figure 1 shows that this decrease was not always continuous, particularly in the earlier conditions, in which some increases in $\log d$ occur with decreases in bulb intensity. This can be attributed to the small number of sessions of training in some of the conditions, in which, when it was clear that subjects were still discriminating very well, the intensity was reduced before discriminability reached its maximum. In Condition 12, when the intensity of the bulb was lowest, only Bird 204 showed good discriminability $(\log d=$ .54). The mean $\log d$ across the remaining 5 subjects was .17. However, when the magnetic field alone was presented during Component 1 in Condition 13, there was once again no discriminability between the two components (Figure 1).

In Condition 14, the bulb onset was coupled with the onset of an auditory stimulus in Component 1 . Figure 1 shows good stimulus control by this complex stimulus. The data from Condition 15 show that this procedure was 

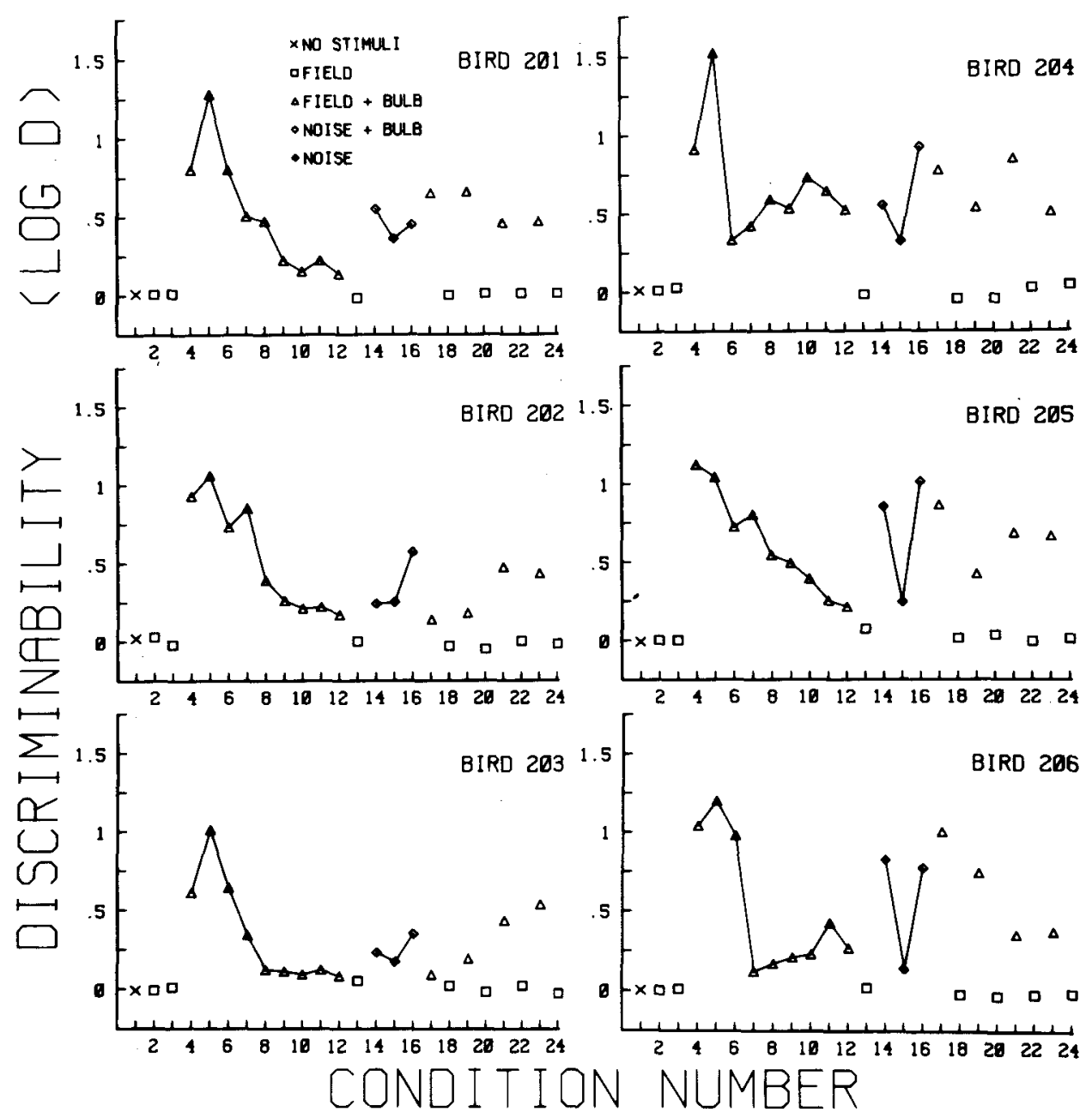

Figure 1. The mean $\log d$ measures from the last four sessions of training in each condition are plotted for each subject in each condition. For conditions with fewer than four sessions of training (Conditions 7,10 , and 11), the data from all sessions were used. The stimuli used in each condition are shown by different symbols. The fading conditions $(4$ to 12$)$ and the noise-discrimination conditions (14-16) are joined by solid lines.

effective in producing discriminative control by the auditory stimulus alone, traditionally a difficult stimulus dimension on which to train pigeons (Rudolph \& Van Houton, 1977). When the onset of the bulb was again coupled with the auditory stimulus in Component 1 of Condition 16, discriminability improved for all subjects.

When the onset of the bulb was coupled with an applied magnetic field of increased intensity in Component 1 of Condition 17, all subjects showed good discriminability between the two components. However, without the bulb lit in Condition 18, the $\log d$ values did not differ significantly from zero (Figure 1).

This pattern was repeated in the remaining conditions. A constant, or pulsing, lit bulb coupled with a pulsing magnetic field in Component 1 produced good discriminability between the two components (Conditions 19, 21, and 23). However, once the bulb was not lit (Conditions
20,22 , and 24), no control by the pulsing applied magnetic field alone could be obtained (Figure 1).

To summarize, although the experimental procedure was effective in producing discriminability between the absence or presence of a variety of light intensities and of an auditory stimulus, no discriminability between the static, or fluctuating, applied magnetic fields and the ambient geomagnetic field was found.

\section{DISCUSSION}

The consistent failure to demonstrate discriminability of the applied magnetic fields necessitates a reappraisal of the experimental procedure. The multiple-concurrent schedule produced good stimulus control when the lit bulb or the more difficult auditory stimulus was used to signal Component 1 . Therefore, at this level, it is reasonable 
to suggest that the training procedure should have been effective in producing stimulus control with the magnetic stimuli.

Another procedural factor that must be considered is the applied magnetic stimulus itself. No data exist as to the range of field strengths or changes in angle of field to which pigeons are sensitive. Indeed, a motivation for the present study was to obtain some quantitative data of this type. Hence, the single electric coil was used to provide a range of field intensities across the face of the keys. Furthermore, any movement between the keys traversed this gradient of field intensities. Pulsing the field during Component 1 should have presented the pigeons with a wide range of fluctuating fields. In effect, the subjects were required to detect the presence or absence of a localized "magnetic storm." However, the data show that all these stimuli were ineffective in producing stimulus control.

If we accept that pigeons are sensitive to magnetic fields, the failure of operant and respondant experiments, including this study, to condition pigeon behavior using magnetic stimuli is of some concern. Bookman (1977) offered a possible explanation for the negative results of these experiments; that is, flight in some form is required for pigeons to detect magnetic fields. Peripheral support for such a hypothesis can be found in some of the physiological models proposed to explain detection of magnetic fields. For example, one possible mechanism involves the action of piezoelectric forces on the features of birds during flight (Tanner \& Romero-Sierra, 1969). However, Bookman's positive result remains an exception in this area. As such, further supporting data are required before his findings can be treated with complete confidence. Other researchers have proposed that magnetic detection is a backup system requiring certain releasing stimuli (e.g., cloudy skies) before it becomes effective (Kirschvink, 1982). Unfortunately, insufficient data exist to evaluate this hypothesis thoroughly.

Be this as it may, the results of the present experiment suggest that providing quantitative data on magnetic detection in pigeons is no simple matter. If pigeons are, indeed, sensitive to magnetic fields, researchers may be compelled to employ experimental designs far more elaborate than those traditionally associated with conditioning procedures before this phenomenon can be investigated within the controlled confines of the laboratory.

\section{REFERENCES}

BAKER, R. R. (1980). A sense of magnetism. New Scientist, 87, 844-846. Benugrand, J. P. (1976). An attempt to confirm magnetic sensitivity in the pigeon, Columba livia. Joumal of Comparative Physiology, 110, 343-355.

BECKER, G. (1963). Magnetfeld-orientierung von dipteren. Naturwissenschaften, 50, 664 .
Bookman, M. (1977). Sensitivity of the homing pigeon to an earthstrength magnetic field. Nature, 267, 340-342.

Davison, M., \& Tustin, R. (1978). The relation between the generalized matching law and signal detection theory. Journal of the Experimental Analysis of Behavior, 29, 331-336.

Gould, J. L., KirschVinK, J. L., Defreyes, K. S., \& BRines, M. L. (1980). Orientation of demagnetized bees. Journal of Experimental Biology, 66, 1-8.

GREEN, D. M., \& Swets, J. A. (1966). Signal-detection theory and psychophysics. New York: Wiley.

KAlmiJn, A. J. (1978). Experimental evidence of geomagnetic orientation in elasmobranch fishes. In K. Schmidt-Koenig \& W. T. Keeton (Eds.), Animal migration, navigation and homing (pp. 347-353). New York: Springer-Verlag.

KalmiJn, A. J., \& Blakemore, R. P. (1978). The magnetic behavior of mud bacteria. In K. Schmidt-Koenig \& W. T. Keeton (Eds.), Animal migration, navigation and homing (pp. 354-355). New York: Springer-Verlag.

Keeton, W. T. (1971). Magnets interfere with pigeon homing. Proceedings of the National Academy of Sciences, 68, 102-106.

KeEton, W. T., LARKIN, T. S., \& Windsor, D. M. (1974). Normal fluctuations in the earth's magnetic field influence pigeon orientation. Journal of Comparative Physiology, 95, 95-103.

KIEPENHEURER, J. (1978). Inversion of the magnetic field during transport: Its influence on the homing behavior of pigeons. In $\mathrm{K}$. SchmidtKoenig \& W. T. Keeton (Eds.), Animal migration, navigation and homing (pp. 135-142). New York: Springer-Verlag.

KIRSCHVINK, J. L. (1982). Birds, bees and magnetism: A new look at the old problem of magnetoreception. Trends in Neurosciences, 5 , 160-167.

Kreithen, M. L., \& KeEton, W. T. (1974). Attempts to condition homing pigeons to magnetic stimuli. Journal of Comparative Physiology, 91, 355-362.

McCarthy, D., Davison, M., \& Jenkins, P. E. (1982). Stimulus discriminability in free-operant and discrete-trial detection procedures. Journal of the Experimental Analysis of Behavior, 37, 199-215.

MEYER, M., \& LAMBE, D. (1966). Sensitivity of the pigeon to changes in the magnetic field. Psychonomic Science, 5, 349-350.

Phillups, J., Alder, K. (1978). Directional and discriminatory responses of salamanders to weak magnetic fields. In K. SchmidtKoenig \& W. T. Keeton (Eds.), Animal migration, navigation and homing (pp. 325-333). New York: Springer-Verlag.

Reille, A. (1968). Essai de mise en évidence d'une sensibilité du pigeon au champ magnétique a l'aide d'un conditionnement nociceptif. Journal de Physiologie (Paris), 60, 85-92.

RudolPH, R. L., \& VAN Houton, R. (1977). Auditory stimulus control in pigeons: Jenkins and Harrison (1960) revisited. Journal of the Experimental Analysis of Behavior, 27, 327-330.

TANNER, J. A., \& Romero-Sierra, C. (1969). Bird feathers as sensory detectors of microwave fields. In S. F. Cleary (Ed.), Symposium on the biological effects and health implications of microwave radiation (Report No. BRHDBE 70-2). Richmond: Virginia Commonwealth University, Bureau of Radiological Health.

Terrace, H. S. (1963). Errorless transfer of a discrimination across two continua. Journal of the Experimental Analysis of Behavior, 6, 223-232.

WALCoTt, C. (1978). Anomalies in the earth's magnetic field increase the scatter of pigeon's vanishing bearings. In K. Schmidt-Koenig \& W. T. Keeton (Eds.), Animal migration, navigation and homing (pp. 145-151). New York: Springer-Verlag.

WALCOTT, C., \& GREEN, R. (1974). Orientation of homing pigeons altered by a change in the direction of an applied magnetic field. Science, $184,180-182$.

(Manuscript received February 6, 1985; revision accepted for publication July 26,1985 .) 